\title{
HOMOIMPLANTE ORTOTÓPICO DE TENDÃO CALCÂNEO EM CÃES. CONSERVAÇÃO, ASSEPSIA E IMPLANTAÇÃO
}

\author{
ORTHOTOPIC HOMOLOGOUS COMMON CALCANEOUS TENDON GRAFT IN DOGS. \\ CONSERVATION, ASEPSIS AND IMPLANTATION
}

\author{
Alceu Gaspar Raiser ${ }^{1}$ Dominguita Lühers Graça ${ }^{2}$ Ney Luis Pippi ${ }^{3}$ Lara Lopes Zinn ${ }^{4}$ \\ Douglas Severo Silveira ${ }^{5}$ Angela Ilha Bordin ${ }^{5}$ Gustavo Cancian Baiotto ${ }^{6}$ \\ Marilaine Vistué Rios ${ }^{5}$ Aron Ferreira da Silveira ${ }^{7}$
}

RESUMO

Foi elaborado um modelo experimental de conser vação, assepsia e implantação de tendão homólogo ortotópico, para avaliar a resposta orgânica, em 48 cães. Os implantes foram conservados em glicerina a 98\%, durante 45 dias a seis meses e, após, reidratados e submetidos à ação anti-séptica do iodo durante 24 antes da implantação. A avaliação clínica $e$ histopatológica após 11, 22, 44 e 132 dias de evolução não evidenciou qualquer sinal de infecção ou rejeição. Tendões homólogos ortotópicos conservados em glicerina a $98 \%$ estão indicados para corrigir perdas tendíneas.

Palavras-chave: cirurgia, trauma, enxerto, transplante.

\section{SUMMARY}

An experimental model of conservation, asepsis and implantation of homologous glycerine $98 \%$-stored tendon graft is presented in order to evaluate the tissue reaction to implantation in 48 dogs. Grafts were preverved in sterile glycerin from 45 days to six months period. Before implantation grafts were placed in isotônic saline with iodine, during 24 period for rehydration and asepsis. Clinical evaluation and histopathologic analisis of biopsies were made at $11^{\text {st }}, 22^{\text {nd }}, 44^{\text {th }}$ and $132^{\text {nd }}$ post-operative day. There was not evidence of infection or graft rejection. Orthotopic homologous glycerine-stored tendon graft are indicated in reconstructive tendon surgery.

Key words: surgery, trauma, graft, transplantation.

\section{INTRODUÇÃO}

A preservação de enxertos pode ser feita por congelamento ou usando agentes químicos como soluções mercuriais, betapropriolactona, glutaraldeído. No Brasil, a glicerina a $98 \%$ tem sido utilizada na esterilização e conservação de membranas biológicas como demonstram as publicações de PIGOSSI (1964), PIGOSSI (1967), INATOMI et al. (1980), DALECK $\boldsymbol{e t}$ al. (1992), COSTA NETO $\boldsymbol{e t}$ al. (1999). As membranas devem ser conservadas em glicerina por período mínimo de 30 dias (DALECK et al., 1992; SARTORI FILHO $\boldsymbol{e}$ t al., 1997; COSTA NETO et al. (1999) havendo relatos de conservação por seis (INATOMI $\boldsymbol{e t} \boldsymbol{a l} .$, 1980) e sete meses (PIGOSSI, 1967).

Qualquer enxerto não autólogo, deve satisfazer alguns critérios: não ser antigênico ou carcinogênico; ser facilmente incorporado pelo hospedeiro e funcionar por toda a vida do receptor; deve estimular as propriedades mecânicas do segmento original e ser facilmente armazenado e implantável. No que concerne à antigenicidade, o tendão é um tecido relativamente hipocelular contendo, principalmente, colágeno maduro. Embora haja pouca dúvida que o colágeno solúvel possa ser específico

\footnotetext{
${ }^{1}$ Médico Veterinário, Professor, Titular, Doutor, Departamento de Clínica de Pequenos Animais (DCPA), Universidade Federal de Santa Maria (UFSM), 97105-900 Santa Maria, RS, Pesquisador do CNPq. Autor para correspondência. E-mail: raisermv@lince.hcv.ufsm.br. Autor para correspondência.

${ }^{2}$ Médico Veterinário, Professor Titular, PhD., Departamento de Patologia, UFSM.

${ }^{3}$ Professor Adjunto, PhD., DCPA, UFSM.

${ }^{4}$ Médico Veterinário, bolsista de aperfeiçoamento CNPq.

${ }^{5}$ Acadêmicos de Medicina Veterinária, bolsistas de iniciação científica do CNPq.

${ }^{6}$ Médico Veterinário, Pós-graduando em Medicina Veterinária, área de cirurgia, UFSM

${ }^{7}$ Médico Veterinário, Professor Adjunto, Departamento de Morfologia, UFSM.
} 
para espécie e possua caráter antigênico, a maioria dos dados prova que o colágeno maduro e insolúvel não é antigênico (VÁMHIDY et al., 1990).

Estudando a conservação de dura-máter homóloga em glicerina, PIGOSSI (1964) verificou que essa solução, além de ser poderoso anti-séptico, desidrata o tecido, substituindo a maior parte da água intracelular sem, entretanto, alterar a concentração iônica das células, protegendo sua integridade. Em pesquisa publicada em 1967, PIGOSSI citou que a glicerina reduz a antigenicidade e preserva a textura de peças de dura-máter canina e humana, nela conservadas; concluiu que, além de atuar como agente fixador e desidratante de atuação rápida, a glicerina tem ação anti-séptica com amplo espectro de ação excetuando-se sobre as formas bacterianas esporuladas. INATOMI et al. (1980) avaliaram a implantação de dura-máter bovina e suína, conservada em glicerina por mais de seis meses, na bainha do músculo reto abdominal de cães. Os autores demonstraram que houve aceitação das membranas, pelo hospedeiro, sem sinais de rejeição.

É fundamental que seja assegurada completa assepsia no uso de transplantes. DEIJKERS $\boldsymbol{e t}$ al. (1997) verificaram que a maior fonte de contaminação é exógena e citaram que a rinçagem com antibiótico é um procedimento comum, o qual diminui apenas a prevalência por bactérias de baixa patogenicidade. A esterilização de metatarsos de gato em óxido de etileno e conservação em glicerina a $98 \%$, por oito semanas, não foram adequadas para esterilizar o vírus da leucemia na cortical desses ossos (CORONADO et al.,1998).

$\mathrm{O}$ iodo-povidine tem efeito rápido e amplo espectro de ação bactericida, fungicida, virucida e, com contato prolongado, esporicida (BAINES (1996). Segundo LEMARIÉ \& HOSGOOD (1995), os compostos iodados têm sido usados na preparação pré-cirúrgica, tópico em feridas e em articulações ou cavidades corporais. Sua atividade esporicida depende de contato, em meio úmido, por tempo superior a 15 minutos. ROBERTS et al. (1986) concluíram que, na diluição 1:50 com solução salina isotônica, o iodo é tão efetivo quanto nas diluições 1:10 e 1:2. STANFORD et al. (1999) constataram que, embora o iodo povidine em solução aquosa a $10 \%$ seja eficiente in vitro, não esteriliza adequadamente enxertos tendíneos infectados por $\boldsymbol{S}$. aureus e $\boldsymbol{P}$. aeruginosa num período de 30 minutos.

Para prevenir infecção cirúrgica durante cirurgia ortopédica, PENWICK (1985) citou o uso da cefalotina, e BUDSBERG \& KEMP (1990) recomendaram as cefalosporinas de primeira geração como a cefalotina, cefradina, cefalexina e cefazolina.
Tecidos conservados são reidratados antes de transplantar por um período variável. SMITH et al. (1996) colheram tendões extensores do membro pélvico de suínos, esterilizaram em óxido de etileno ou irradiação e conservaram por congelamento a seco, testando-os após descongelamento e hidratação. O tempo necessário para reidratação variou com a forma e tamanho, levando até $24 \mathrm{~h}$, e os enxertos arredondados e grandes tomaram relativamente mais tempo.

Considerando as características antisépticas do iodo e o tempo necessário à reidratação de tendões, foi objetivo desta pesquisa avaliar a resposta orgânica ao implante ortotópico de tendão calcâneo, conservado em glicerina a 98\%, e submetido a assepsia e hidratação com solução aquosa de iodo.

\section{MATERIAL E MÉTODOS}

Foi efetuada coleta de tendões calcâneos de cães, em sala de necropsia, imediatamente após o óbito, sendo os membros doadores tricotomizados, higienizados com solução salina isotônica, e as mãos do operador protegidas por luvas esterilizadas.

Cada segmento tendíneo foi lavado em solução salina e, logo após, imerso em um frasco de vidro com capacidade para $250 \mathrm{~m} \ell$, contendo $200 \mathrm{~m} \ell$ de glicerina estéril a 98\%, que teve identificação do período de coleta, da idade, peso e história clínica do doador. Os frascos foram armazenados à temperatura ambiente $\left(22 \mathrm{a} 28^{\circ} \mathrm{C}\right)$ em armário apropriado.

Vinte e quatro cães sem raça definida, sadios, provenientes do Biotério Central da Universidade Federal de Santa Maria, foram desverminados, submetidos a exame clínico e hematológico e adaptados ao consumo de ração comercial. Os animais, com idade estimada entre um e dois anos, com peso ao redor de $12 \mathrm{~kg}$, sofreram tenectomia do tendão calcâneo esquerdo e o defeito foi reconstituído, logo após, com homoimplante de tendão conservado em glicerina a $98 \%$. Os cães foram separados em dois grupos, conforme o método de imobilização da articulçação tibio-társica e, em quatro subgrupos de igual número, para coleta de biópsias, aos 11, 22, 44 e 132 dias de evolução.

Vinte e quatro horas antes da implantação, os tendões conservados em glicerina a $98 \%$ foram mergulhados em $100 \mathrm{~m} \ell$ de solução hidroeletrolítica balanceada, contendo $2 \mathrm{~m} \ell$ de polividona ${ }^{\mathrm{a}}$ a $10 \%$ ( $1 \%$ de iodo ativo) em veículo aquoso, tamponado para $\mathrm{pH}$ 5,5.

Submetido a jejum sólido de $12 \mathrm{~h}$ e líquido de $6 \mathrm{~h}$, cada animal recebeu $20 \mathrm{mg} / \mathrm{kg}$ de ampicilina sódica, via venosa, 30 minutos antes da cirurgia e foi 
pré-medicado com acepromazina $(0,1 \mathrm{mg} / \mathrm{kg})$ associada com citrato de fentanila $(0,005 \mathrm{mg} / \mathrm{kg})$, induzido com tiopental sódico $(5-10 \mathrm{mg} / \mathrm{kg})$, e a anestesia foi mantida com halotano vaporizado em oxigênio a $100 \%$. A cirurgia foi feita sob rigorosa assepsia e, durante a intervenção, foi administrada solução poliônica em gotejamento venoso de $10 \mathrm{~m} \ell / \mathrm{kg} / \mathrm{h}$.

O tendão calcâneo foi abordado pela face medial e resseccionado um segmento intermediário de modo que restasse $1 \mathrm{~cm}$ da estrutura na junção teno-óssea e $1 \mathrm{~cm}$ na tenomuscular. Após hemostasia, o implante homólogo, já hidratado (Figura 1a), foi transplantado para o leito receptor. Em três cães de cada subgrupo, foi implantado tendão conservado em glicerina a $98 \%$ por até três meses e, nos outros três, entre três e seis meses.

As anastomoses foram feitas com fio mononáilon 4-0 pela técnica de Kessler modificada e 50 para síntese do paratendão, em pontos isolados simples. Os planos abordados foram reconstituídos com mononáilon 5-0 e a articulação imobilizada, em ângulo de flexão de aproximadamente $135^{\circ}$, por 21 dias. Em metade dos cães, a articulação tíbio-társica foi imobilizada com um parafuso cortical (MILTON

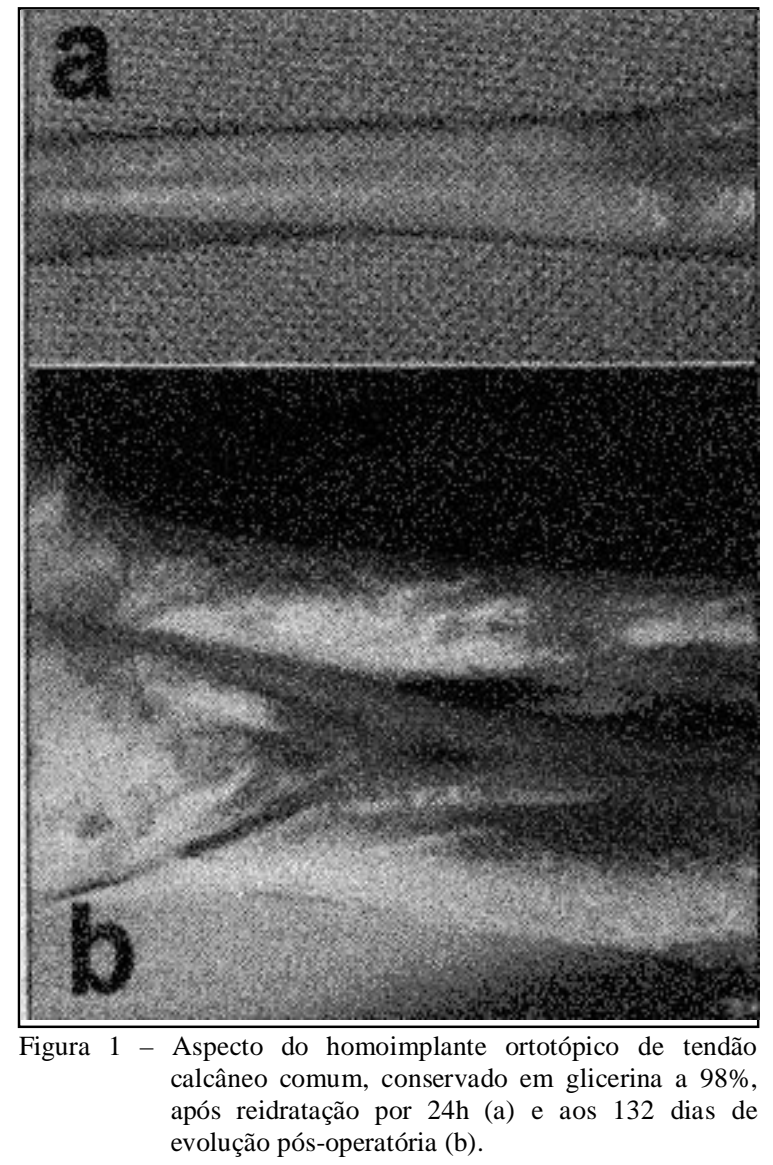

\& HENDERSON, 1986) e nos demais por meio de uma calha construída de arame galvanizado e esparadrapo (BAIOTTO et al., 1998).

Para avaliação clínica, que iniciou no pósoperatório imediato, foi efetuada inspeção diária, anotando-se, particularmente, a condição clínica geral e a evolução da área operatória.

Um cão do grupo com imobilização interna e outro do grupo com imobilização externa (eleitos por sorteio) foram sacrificados aos132 dias de evolução e, nos demais, foram efetuadas abordagem cirúrgica e biópsia. Para obtenção das amostras, os animais foram anestesiados conforme o protocolo descrito inicialmente e submetidos à cirurgia asséptica. De cada membro, foi obtido um segmento compreendendo o implante e $0,5 \mathrm{~cm}$ do tendão receptor adjacente. Cada amostra foi identificada, fixada em formol neutro, processada e corada pelo método Hematoxilina e Eosina, para observar a evolução do processo cicatricial.

\section{RESULTADOS E DISCUSSÃO}

O tempo de conservação, em glicerina a $98 \%$, dos tendões implantados, foi de 45 dias a 6 meses, portanto, dentro do período recomendado por PIGOSSI (1967), INATOMI et al. (1980), SARTORI FILHO et al. (1997) e COSTA NETO (1999), e foi suficiente para prevenir reação de rejeição, a qual não foi presenciada em nenhum dos cães. Assim, o período mínimo de preservação é que tem maior importância pois, segundo DALECK et al. (1992), são necessários ao menos 30 dias de conservação na glicerina para que o implante perca sua capacidade de estimular reação imunológica. Embora VÁMHIDY et al. (1990) tenham citado que o colágeno maduro e insolúvel não é antigênico, a preservação em glicerina é importante, pois, segundo PAYNE \& TOMLINSON (1993), o tendão tem, em sua composição, substância básica, vasos e tecido conjuntivo que podem induzir reação de antigenicidade.

As características físicas de consistência e maleabilidade do tendão conservado em glicerina, após reidratação, não se igualaram a do tendão receptor, mesmo após o período de $24 \mathrm{~h}$. Os tendões aqui utilizados (Figura 1a) tinham a conformação arredondada que, segundo SMITH et al. (1996), leva mais tempo para reidratar. Aparentemente, tendões preservados em glicerina também demoram mais para reidratar e parece haver relação com o tempo de preservação, pois os tendões conservados por mais de três meses mantiveram-se mais rígidos. Deduz-se que a conservação prolongada de tendões cause um 
grau de desidratação que pode não ser compensado completamente em $24 \mathrm{~h}$. Essa variação não causou, no entanto, reação tecidual diferenciada quando comparada aos preservados por menor tempo. Os tendões foram, progressivamente, envolvidos por tecido fibroso proliferante, sem sinais de rejeição e, aos 132 dias de evolução (Figura 1b) todos se apresentavam funcionais, porém os componentes desse grupo tendíneo não eram individualizados ao exame macroscópico.

A manutenção do implante em solução contendo iodo $1 \%$ e $\mathrm{NaCl}$ 0,9\% em diluição 1:50, por $24 \mathrm{~h}$, teve por finalidade obter hidratação do mesmo e controle de possíveis agentes infectantes, resistentes à glicerina. A preocupação com a infecção é procedente, pois, em 1964 e 1967, PIGOSSI já citou que, embora fosse um poderoso anti-séptico, a glicerina não atuou sobre microorganismos esporulados. Além disso, as pesquisas de DEIJKERS et al. (1997) demonstraram que tendões de Aquiles, coletados de cadáveres humanos, sofreram contaminação exógena por bactérias resistentes aos antibióticos, comumente utilizados na rinçagem de enxertos; e os de CORONADO et al. (1998) indicaram a presença do vírus da leucemia felina, em ossos conservados em glicerina.

Segundo STANFORD et al. (1999), embora bactérias fossem sensíveis ao iodo a $10 \%$ sob ação direta, não o foram quando inoculadas em enxertos tendíneos mergulhados na mesma solução, por um período de 30 minutos. E esse é o período, comumente, utilizado para assegurar esterilização das membranas conservadas na glicerina a $98 \%$, sob a ação de diferentes antibacterianos. Considerando que, para SMITH et al. (1996), o período recomendado para hidratação de um enxerto tendíneo redondo deva ser de até $24 \mathrm{~h}$, a solução iodada não alcançaria a porção interna do tendão em tempo inferior e, por conseqüência, não exerceria uma completa ação anti-séptica.

O protocolo antibacteriano adotado, na presente pesquisa, foi elaborado com base nos resultados apresentados por SMITH et al. (1996) e DEIJKERS et al. (1997) e sua eficiência foi comprovada pela ausência de sinais de infecção, na evolução pós-cirúrgica. A opção pelo iodo, como antibacteriano, justifica-se por seu amplo espectro de ação, incluindo fungos, vírus e esporos, conforme citaram LEMARIÉ \& HOSGOOD (1995) e BAINES (1996); e a diluição da apresentação a 1\%, na proporção de 1:50 com solução salina, baseou-se no trabalho de ROBERTS et al. (1986) os quais demonstraram ser, esta, tão eficiente quanto aquelas mais concentradas. Os resultados publicados por
STANFORD $\boldsymbol{e t}$ al. (1999) confirmam que a decisão de manter o implante mergulhado na solução aquosa de iodo, por 24 horas, fora acertada.

A ampicilina sódica foi utilizada com a finalidade específica de prevenir a instalação de bactérias que, eventualmente, contaminassem $o$ campo operatório. Embora seja um antibiótico de espectro limitado e não seja o mais indicado para profilaxia em cirurgia ortopédica, em que PENWICK (1985) e BUDSBERG \& KEMP (1990) recomendam as cefalosporinas, foi eficiente, pois nenhum dos pacientes apresentou infecção no pósoperatório.

Em nenhuma das fases evolutivas em que se efetuaram as biópsias, foi constatada reação inflamatória polimorfonuclear que caracterizasse infecção. Esse dado, associado ao tipo de proliferação tecidual encontrado, predominantemente tecido conjuntivo reparador, demonstraram que o implante, o procedimento cirúrgico e a evolução pósoperatória ocorreram de forma asséptica e a reação tecidual foi do tipo reparadora.

Tanto os cães do grupo submetido à imobilização externa, quanto interna, recuperaram progressivamente a deambulação após os 21 dias e, duas semanas depois todos se locomoviam sem claudicação. Em quatro animais com o membro sob imobilização externa, ocorreu aumento da flexão articular de, aproximadamente, 5 graus que foi recuperado, até os 44 dias de evolução, apenas com a deambulação. Esse resultado mostra que a imobilização externa confere estabilização menos rígida e pode favorecer um grau mais acentuado de proliferação tecidual nas anastomoses, como se observa ao exame microscópico na figura $2 \mathrm{~b}$, devido à distensão pela sustentação do peso.

Os achados histológicos, aos 11 dias (Figura 2a) de evolução, mostram o processo inicial de reparação caracterizado por inflamação, predominando células mononucleares e neoformação vascular rodeando os implantes ou entre esses e o tendão receptor nas anastomoses. Aos 22 dias (Figura 2b), o processo inflamatório ainda mostra vasos invadindo os implantes, verificando-se áreas mais extensas de hialinização, seguidos por fibroblastos de conformação mais arredondada. Esses achados caracterizam um processo em que o implante começa a ser reabsorvido e substituído por tecido fibroso neoformado, o qual era exuberante ao redor do mesmo.

Aos 44 dias de evolução (Figura 2c), as amostras apresentaram implante com feixes de fibras bem alinhadas, ainda com aspecto hialinizado, eosinofílicas, separadas por tecido conjuntivo tênue e vasos sangüíneos. No tecido conjuntivo proliferante, o número de células inflamatórias mononucleares 


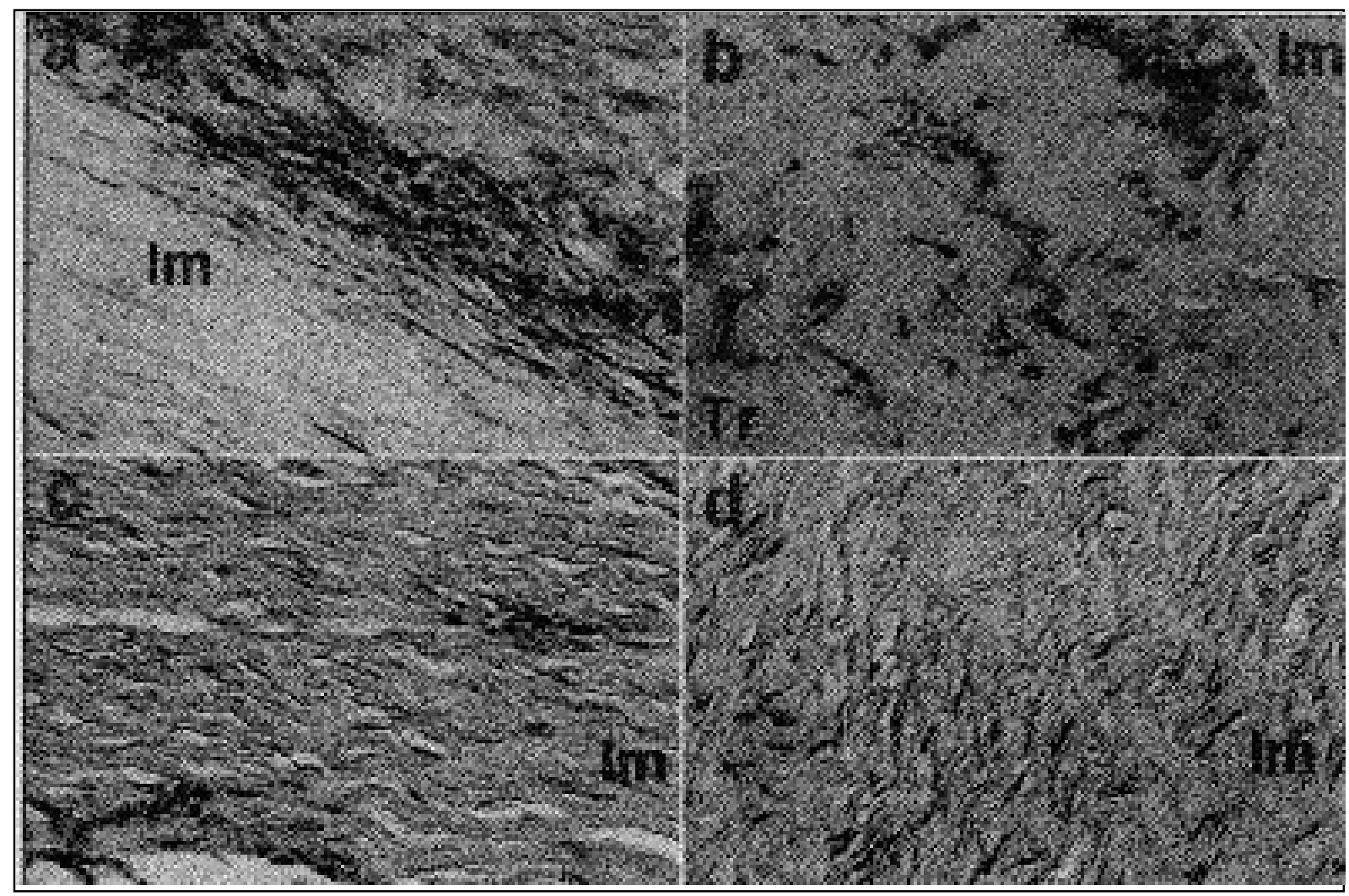

Figura 2 - Aspecto histológico do homoimplante ortotópico de tendão calcâneo de cão, conservado em glicerina a 98\% (HE 16X). Aos 11 (a) e 22 dias (b) de evolução, observam-se o implante (Im) hialinizado, envolto por tecido fibroso, e a presença de células mononucleares ao redor do mesmo (a) e na anastomose (b); aos 44 dias de evolução (c)o número de células mononucleares é menor e, aos 132 dias (d), verificam-se apenas fibroblastos mais fusiformes. ( $\mathrm{Tr}$ - tendão receptor).

era significativamente menor que nos períodos anteriores, e localizado, predominantemente, junto aos vasos. Os fibroblastos mostravam núcleos mais ovalados que nas amostras com menor tempo de evolução, em que eram mais arredondados, indicando, ainda, fase ativa de síntese colágena. Para esse achado corrobora WANG (1998), o qual, estudando a cicatrização de tendões, citou que o colágeno é depositado até os 42 dias de evolução.

Aos 132 dias (Figura 2d), embora os tendões já mostrassem feixes de fibras bem alinhadas e fibroblastos fusiformes que, segundo PAYNE \& TOMLINSOM (1993), é característico do tendão maduro, ainda se verificou amostras com atividade celular e fibras desorganizadas. Esses resultados estão dentro do cronograma evolutivo, pois, de acordo com AUTEFAGE (1999), que efetuou estudo sobre a reparação tendínea e de ligamentos, em cães, a cicatrização não se completa antes de um ano de evolução.

A utilização de implante ortotópico buscou atender à perda tendínea de origem traumática, a qual tem sido corrigida com membranas biológicas, como mostram os trabalhos de SARTORI FILHO et al. (1997) e COSTA NETO et al. (1999). Considerase que o implante de tendão homólogo, ortotópico, conservado em glicerina a 98\%, atende às qualidades requisitadas por VÁMHIDY et al., (1990) de ser facilmente armazenado e implantável. Pode-se acrescentar, também, a vantagem de evitar trauma icional na área doadora e ter a mesma identidade da estrutura receptora.

\section{CONCLUSÕES}

$\mathrm{Na}$ vigência dos resultados obtidos no presente experimento, é pertinente concluir que o homoimplante ortotópico de tendão calcâneo, conservado em glicerina a $98 \%$, e imerso em solução salina isotônica, com iodo polividona, por $24 \mathrm{~h}$, para adequada hidratação e esterilização, não desencadeia sinais característicos de infecção ou rejeição, depois de implantado.

\section{FONTES DE AQUISIÇÃO}

a - HI-ODIN: Halex Istar Indústria Framacêutica Ltda. 


\section{REFERÊNCIAS BIBLIOGRÁFICAS}

AUTEFAGE, A. La cicatrizzazione dei tendini e dei ligamenti. Summa, Italia, v.16, n.1, p.29-34, 1999.

BAIOTTO, G.C., ZINN, L.L., RAISER, A.G., et al.. Proposição de molde para imobilização externa da articulação do tarso. In: CONGRESSO BRASILEIRO DE CIRURGIA E ANESTESIOLOGIA VETERINÁRIA， 3, 1998, Belo Horizonte. Anais... Belo Horizonte : CBCAV, 1998. p.89.

BAINES, S. Surgical asepsis: principles and protocols. In Practice, London, v.18, n.1, p.23-33, 1996.

BUDSBERG, S.C., KEMP, D.T. Antimicrobial distribution and therapeutics in bone. Comp Cont Educ Pract Vet, Trenton, v.12, n.12, p.1758-1763, 1990.

CORONADO Jr, G.S., MARTINEZ, S.A., SWENSON, C.L. Virucidal and osteogenic effects of $98 \%$ glycerol and ethylene oxide preservation of bone allograft in the cat. In: ANNUAL CONFERENCE OF VETERINARY ORTHOPEDIC SOCIETY, 25, 1998, Snowmass, Colorado, USA. Proceedings... Montreal : Veterinary Orthopedic Society, 1998. p.31.

COSTA NETO, J.M., DALECK, C.R., ALESSI, A.C., et al. Tenoplastia experimental do calcâneo em cães com peritônio bovino conservado em glicerina. Ciência Rural, Santa Maria, v.29, n.4, p.697-703, 1999.

DALECK, C.R., DALECK, C.L.M., PADILHA FILHO, J.G., $\boldsymbol{e}$ al. Reparação de hérnia perineal em cães com peritônio de bovino conservado em glicerina. Ciência Rural, Santa Maria, v.22, n.2, p.179-183, 1992.

DEIJKERS, R.L.M., BLOEM, R.M., PETIT,P.L.C. $\boldsymbol{e}$ t al. Contamination of bone allografts. Analysis of incidence and predisposing factors. J Bone Joint Surg, (Br), London, v.79B, n.1, p.161-166, 1997.

INATOMI, L.S., PRANTONI, G.A., RAISER, A.G., $\boldsymbol{e t}$ al. Implante de dura-máter heteróloga em cães. Rev Centro Ciências Rurais, Santa Maria, v.10, n.3, p.291-297, 1980

LEMARIÉ, R.J., HOSGOOD, G. Antiseptics and disinfectants in small animal practice. Comp Cont Educ Pract Vet, Trenton, v.17, n.11, p.1339-1352, 1995.
MILTON, J.L., HENDERSON, R.A. Músculos e tendões. In: BOJRAB, M.J. (Ed). Cirurgia dos pequenos animais. 2 ed. São Paulo : Roca, 1986. Cap.38. p.536-560.

PAYNE, J.T., TOMLINSOM, J.L. Composition, structure, and function of muscle, tendon and ligament. In: BOJRAB, M.J. (Ed.). Disease mechanisms in small animal surgery. 2 ed. Philadelphia : Lea \& Febiber, 1993. Cap.95. p.656-662.

PENWICK, R.C. Preoperative patient preparation. In: NEWTON, C.D., NUNAMAKER, D.M. (Eds.). Textbook of small animal orthopaedics. Philadelphia : Lippincott, 1985. Cap.9. p.167-176.

PIGOSSI, N. Implantação de dura-máter homógena conservada em glicerina. São Paulo, 1964. 41p. Tese (Doutorado) - Faculdade de Medicina de São Paulo, Universidade de São Paulo, 1964.

PIGOSSI, N. A glicerina na conservação de dura-máter. São Paulo, 1967. 36 p. Tese (Livre-Docência) - Faculdade de Medicina de São Paulo, Universidade de São Paulo, 1967.

ROBERTS, S.M., SEVERIN, G.A., LAVACH, J.D Antibacterial activity of dilute povidone-iodine solutions used for ocular surface desinfection in dogs. Am J Vet Res, Schaumburg, v.47, n.6, p.1207-1210, 1986.

SARTORI FILHO, R., GANDOLFI, W., BANDARRA, E.P. Emprego de membrana biológica (centro frênico) na reparação das lesões tendíneas em coelhos. Vet e Zoot, São Paulo, v.9, p.69-77, 1997.

SMITH, C.W., YOUNG, I.S., KEARNEY, J.N. Mechanical properties of tendons with sterilization and preservation. $\mathbf{J}$ Biomech Eng, New York, v.118, n.1, p.56-61, 1996.

STANFORD, R., SOLOMON, M. LEVICK, M. et al. Sterilization of contaminated bone-tendon autografts using 10\%povidone-iodine solution. Orthopedics, Thorofare, v.22, n.6, p.601-604, 1999.

VÁMHIDY, L., STRAUCH, B., BIRÓ, V. Preserved tendon grafts in reconstructive hand surgery: a review. Acta Chir Hung, Budapest, v.31, n.3, p.209-215, 1990.

WANG, D.E. Tendon repair. J Hand Ther, Philadelphia, v.11, n.2, p.105-110,1998.

Ciência Rural, v. 31, n. 1, 2001. 